\title{
The importance of combinatorial gene expression in early mammalian thalamic patterning and thalamocortical axonal guidance
}

\author{
David J. Price ${ }^{1}{ }^{*}$, James Clegg ${ }^{1}$, Xavier Oliver Duocastella ${ }^{1,2}$, David Willshaw ${ }^{2}$ and Thomas Pratt ${ }^{1}$ \\ Centre for Integrative Physiology, University of Edinburgh, Edinburgh, UK \\ ${ }^{2}$ School of Informatics, University of Edinburgh, Edinburgh, UK
}

Edited by:

Steffen Scholpp, Karlsruhe Institute of Technology, Germany

\section{Reviewed by:}

Gonzalo Alvarez-Bolado, University of Heidelberg, Germany

Seth Blackshaw, Johns Hopkins

University School of Medicine, USA

\section{*Correspondence:}

David J. Price, Centre for Integrative Physiology, University of Edinburgh, Hugh Robson Building, George Square, Edinburgh EH8 9XD, UK. e-mail:david.price@ed.ac.uk
The thalamus is essential for sensory perception. In mammals, work on the mouse has taught us most of what we know about how it develops and connects to the cortex. The mature thalamus of all mammalian species comprises numerous anatomically distinct collections of neurons called nuclei that differ in function, connectivity, and molecular constitution. At the time of its initial appearance as a distinct structure following neural tube closure, the thalamus is already patterned by the regional expression of numerous regulatory genes. This patterning, which lays down the blueprint for later development of thalamic nuclei, predates the development of thalamocortical projections. In this review we apply novel analytical methods to gene expression data available in the Allen Developing Mouse Brain Atlas to highlight the complex organized molecular heterogeneity already present among cells in the thalamus from the earliest stages at which it contains differentiating neurons. This early patterning is likely to invest in axons growing from different parts of the thalamus the ability to navigate in an ordered way to their appropriate area in the cerebral cortex. We review the mechanisms and cues that thalamic axons use, encounter, and interpret to attain the cortex. Mechanisms include guidance by previously generated guidepost cells, such as those in the subpallium that maintain thalamic axonal order and direction, and axons such as those of reciprocal projections from intermediate structures or from the cortex itself back toward the thalamus. We show how thalamocortical pathfinding involves numerous guidance cues operating at a series of steps along their route. We stress the importance of the combinatorial actions of multiple genes for the development of the numerous specific identities and functions of cells in this exquisitely complex system and their orderly innervation of the cortex.

Keywords: thalamus, cortex, transcription factor, axon guidance, guidance molecule, transgenic mouse, thalamocortical axon, pioneer axon

\section{INTRODUCTION}

\section{AN OVERVIEW OF THALAMIC STRUCTURE AND FUNCTION}

The thalamus is a bilaterally symmetrical structure located roughly centrally in the forebrains of mammals (Figure 1). In adults, its neurons are clustered into discrete groups called nuclei that are easily recognized in histological sections. Some nuclei connect a single functional pathway: for example, the dorsal lateral geniculate nucleus (LGN) receives axons from the retina and is connected to the visual cortex. The best-studied nuclei are those through which sensory information flows from the periphery to the cortex, namely the dorsal LGN (visual), the ventral complex (somatosensory), and medial geniculate complex (auditory; Figure 1). These sensory nuclei are found in a region of the thalamus traditionally called the dorsal thalamus to distinguish it from its neighbor, the ventral thalamus, which contains nuclei whose functions are less well understood and do not connect to the cortex. In fact, as one moves along the curved anteroposterior axis of the neural tube, the ventral thalamus is found anterior to the dorsal thalamus rather than ventral to it and the preference now is to refer to the dorsal thalamus as simply "the thalamus" and the ventral thalamus as "the prethalamus" (indicating its location before the thalamus). This nomenclature will be adopted here.

Each thalamic nucleus connects either to a specific cortical region or over a broader area comprising several related regions. Electrophysiological and axonal tracing methods have shown that the connections of the principal sensory nuclei project in an ordered topographical manner to the cortical area they innervate, generating maps of the sensory surface. It is estimated that between 70 and $99 \%$ of thalamic neurons project to the cortex and, across mammalian species, the size of the thalamus is proportional to the size of the cortex (Sherman and Guillery, 2005; Jones, 2007). Nuclei whose main role is to relay and process sensory information often have their neurons organized into discrete subregions, in some cases into layers, that relay specific aspects of the sensory modality they receive. For example, in the rodent whisker system, distinct types of sensory information such as that regarding touch versus movement of the whiskers is transmitted by separate components of the somatosensory nuclei. The thalamus is 
more than merely a relay of information to the cortex. It has a much more active role, with information coming to the cortex being altered through cortical feedback via corticothalamic axons and the involvement of the reticular nucleus of the prethalamus (Figure 1; Sherman, 2007). Nuclei such as those near the midline (Figure 1) have been linked to general properties of the normal functioning brain, such as attention, arousal, and awareness (Van der Werf et al., 2002).

Thus, the thalamus and prethalamus are divisible and subdivisible into a highly complex set of anatomically and functionally distinct regions. As described in later sections, this complexity starts to be generated from the earliest embryonic stages at which the thalamus and prethalamus are first recognizable as a distinct structure, soon after closure of the neural tube.

\section{AN OVERVIEW OF THE ANATOMICAL DEVELOPMENT OF THALAMUS AND ITS CONNECTIONS}

In the mammalian embryo, the folding of the neural plate and its closure along the dorsal midline to form the neural tube generates the spinal cord posteriorly and the brain anteriorly. The early brain comprises three main vesicles, the forebrain (or prosencephalic) vesicle, the midbrain (or mesencephalic) vesicle, and the hindbrain (or rhombencephalic) vesicle. The forebrain vesicle expands to form two bilateral telencephalic vesicles and a central diencephalic vesicle that becomes engulfed by the more rapidly expanding telencephalic vesicles that rise up on either side of it. The telencephalon generates the cerebral cortex in its dorsal component (known as the pallium) and the basal ganglia in its ventral component (known as the subpallium). The major derivatives of

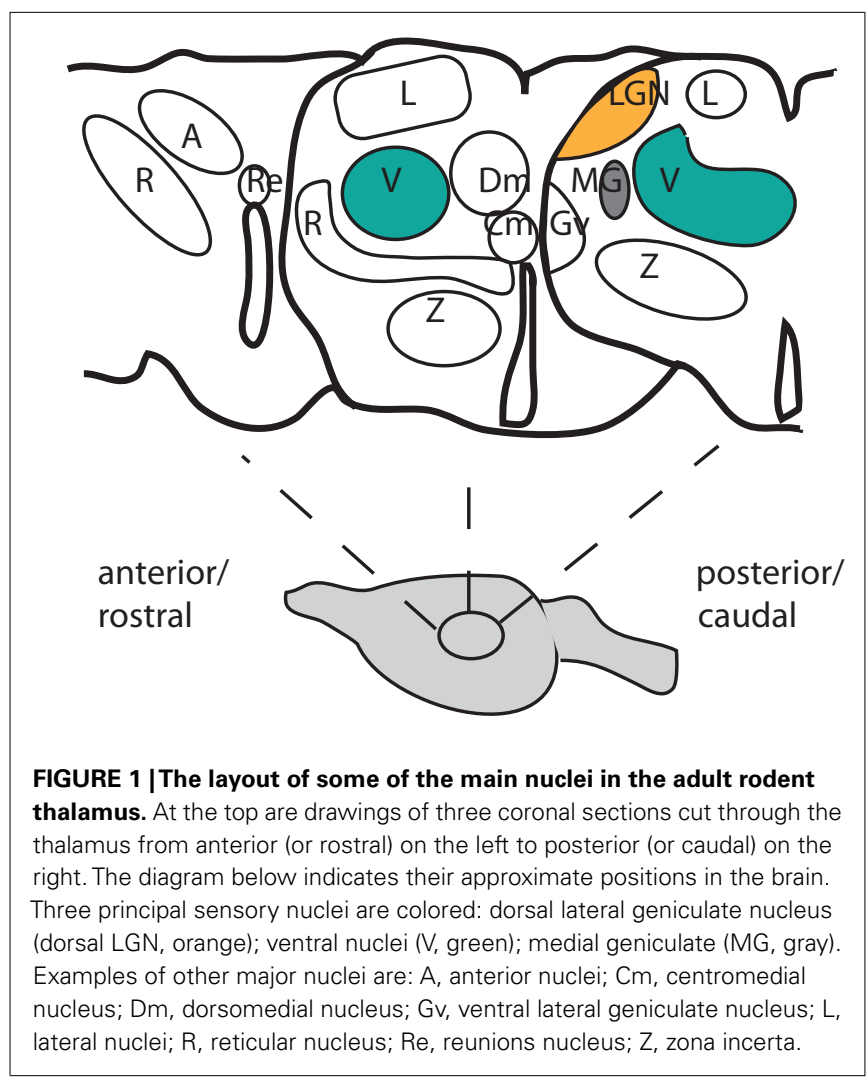

the diencephalon are the thalamus, hypothalamus, prethalamus, and epithalamus.

The thalamocortical tract, which comprises the axons of thalamic neurons that innervate the cortex, starts to form soon after the thalamus and prethalamus develop as distinct anatomical entities and continues to grow and expand at the same time as thalamic nuclei emerge and mature. This makes it likely that the mechanisms of thalamic nuclear formation and thalamocortical axonal development are intimately intertwined. The formation of the thalamocortical tract is achieved by the guidance of growing axons from their cell bodies within the thalamus through a complex three-dimensional route to the cortex (Figure 2). The fact that thalamic axons take such a complex route over a relatively

A

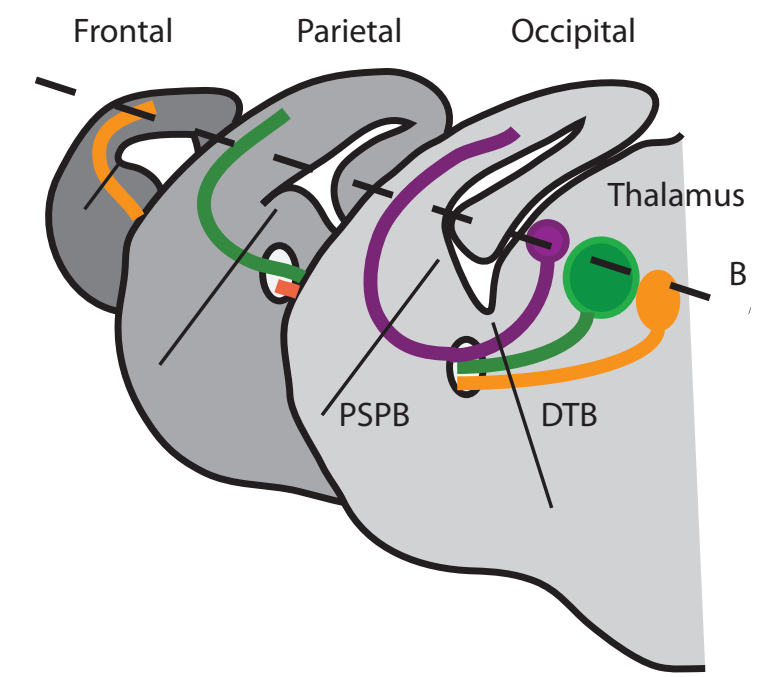

B

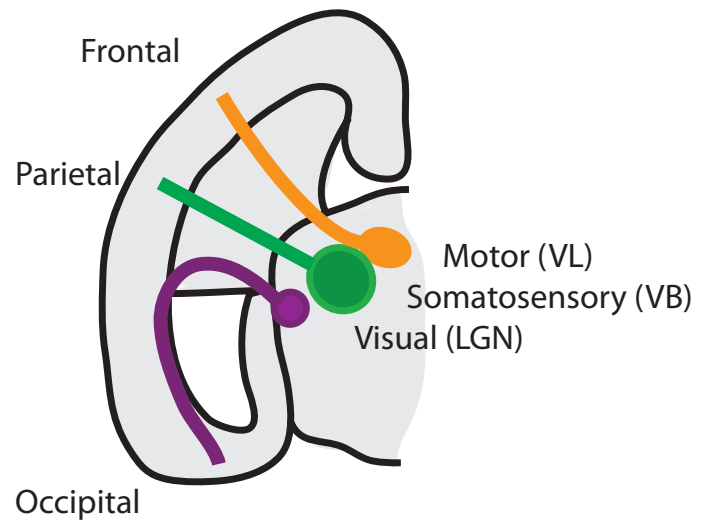

FIGURE 2 |The three-dimensional topography of thalamocortical connections in the mouse brain. (A) Three coronal sections through the brain around the time of birth, from anterior on the left to posterior on the right. Axons from different thalamic nuclei project in topographic order to innervate their specific cortical regions: dorsal lateral geniculate nucleus (dorsal LGN) innervates occipital (visual) cortex (purple); ventrobasal nuclei (VB) innervate parietal (somatosensory) cortex (green); ventrolateral nuclei (VL) innervate frontal (motor) cortex (orange). Thalamocortical axons cross the diencephalic-telencephalic boundary (DTB) and the pallial-subpallial boundary (PSPB). (B) Horizontal section taken in the plane shown by broken line in (A). 
long distance makes this tract a particularly fascinating example in which to analyze the mechanisms of axon guidance and suggests that the guidance mechanisms are likely to be multiple.

Initially, thalamocortical axons extend anteroventrally through the prethalamus; they then turn laterally into the ventral part of the telencephalon, or subpallium, by crossing the diencephalictelencephalic boundary (DTB); finally, they turn once again, this time dorsally, to reach the cortex in the pallium by crossing the pallial-subpallial boundary (PSPB; Figure 2). At the same time, axons extend from the cortex along the same path, forming reciprocal corticothalamic connections with the thalamus (reviewed by López-Bendito and Molnár, 2003; Price et al., 2006). The thalamus and cortex are interconnected in an ordered fashion such that adjacent cells in the presynaptic structure project, as a general rule, to adjacent structures in the postsynaptic structure. Thalamocortical axons are ordered as they grow through the subpallium toward the cortex, indicating that topography is present in the tract before axons arrive at their final target (reviewed in Garel and Rubenstein, 2004). A detailed understanding of the precision of this topography is still elusive. One issue that needs to be resolved is exactly how a collection of thalamic nuclei and sub-nuclear structures distributed in threedimensional space in the thalamus and a set of points distributed across the two dimensions (rostrocaudal and mediolateral) of the cortical sheet map onto each other. To what extent are the neighbor-relationships of axons from adjacent neurons in one structure maintained as they grow to the other? At present, our insight into the topography of thalamocortical projections remains relatively crude.

\section{MOLECULAR PATTERNING OF THE DEVELOPING THALAMUS PREVIOUS STUDIES}

For thalamocortical axons to navigate a complex route through the forebrain while maintaining some degree of topographic order they need to be equipped with the molecules necessary to allow appropriate responses to the guidance cues they will encounter from other cell bodies or axons, including those of other thalamic neurons. One important way in which topographic order might be maintained is that the neurons of cells in different parts of the developing thalamus might express different sets of such molecules, preventing them from becoming mixed up. In other words, the pattern of molecules expressed across the thalamus might be critical for ensuring appropriate navigation. There is now strong evidence that this is the case.

The establishment of inter-neuronal differences in the expression of molecules involved in axon guidance, such as receptors for extracellular guidance cues, is controlled by the thalamic expression of transcription factors that determine which of the genes that encode such cues are activated or repressed in any particular cell. A critical question, therefore, is whether, and if so to what extent, different regions of the thalamus express different sets of regulatory transcription factors and downstream guidance molecules, such as receptors, before they start to grow axons toward the cortex. The sets of genes expressed within each thalamic region are certain to overlap partially and the molecular identity of each region will depend on the combination of transcription factors that it expresses and their levels.
By about halfway through gestation in mice, the thalamus comprises the progenitor cells that will generate most of the postmitotic thalamic neurons over the following days. A study by Vue et al. (2007) defined two major progenitor domains in the thalamus, one large posterior domain named $\mathrm{pTH}-\mathrm{C}$ that expresses transcription factors such as Ngn2 and Olig2 and a much smaller anterior domain named PTH-R that expresses transcription factors such as Nkx2.2 and Mash1 (Figure 3). At a finer level, several detailed and elegant expression analyses have shown that from an age before thalamocortical axons start to navigate to the cortex thalamic progenitors and their newly generated postmitotic neurons are subdivided molecularly by the expression of transcription factors and other molecules into regions that are likely to be the forerunners of the thalamic nuclei of the mature structure (Nakagawa and O'Leary, 2001; Vue et al., 2007, 2009; Kataoka and Shimogori, 2008; Suzuki-Hirano et al., 2011; Yuge et al., 2011). More work is required to determine the relationship between these early patterns of thalamic gene expression and specific mature thalamic nuclei. Most previous studies looked for possible correspondence between the early expression of individual genes and the later development of specific thalamic nuclei and further insights might be gained by examining the early patterning conferred by combinations of transcription factors, since cells that co-express one particular combination are likely to develop differently to cells that express a different combination even if some of the individual genes expressed are the same. In the following section we describe an analysis using existing data on the expression of individual genes to deduce patterns of co-expression of these genes. The results of a theoretical analysis such as this might guide us toward combinations of genes that might be most worth studying experimentally.

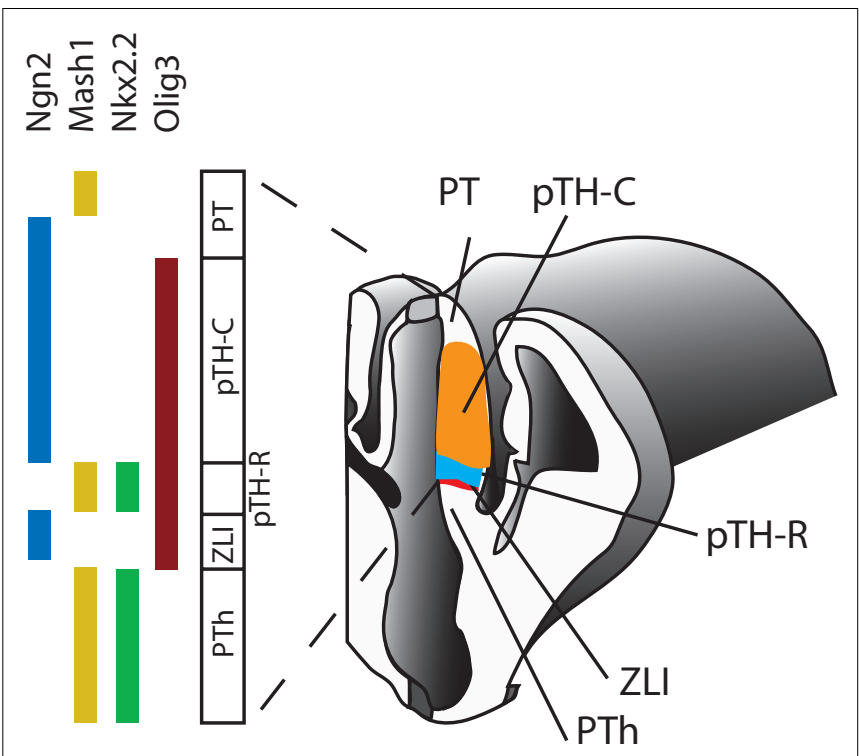

FIGURE 3 | Examples of transcription factor expression patterns in the progenitor domain of the embryonic mouse diencephalon. The thalamus is divided into the large pTH-C (orange) and the small anterior pTH-R (blue). Abbreviations: PT, pretectum; PTh, prethalamus; ZLI, zona limitans intrathalamica. Adapted from Vue et al. (2007). 


\section{AN ANALYSIS OF EXISTING DATA IN THE ALLEN DEVELOPING MOUSE BRAIN ATLAS}

The Allen Developing Mouse Brain Atlas (ADMBA) contains images of both Feulgen Yellow DNA counterstained $20 \mu \mathrm{m}$-thick tissue coronal sections through mouse embryonic brains and in situ hybridizations providing data on the expression of a wide range of genes that pattern the early thalamus. Its detail and highresolution images give it the potential to be a powerful resource for the analysis of gene expression and co-expression patterns. Such data has many possible uses. For example, previous work has developed methods for semi-automatic annotation of gene expression patterns as a step toward generating atlases of the expression of all genes in the brain (Carson et al., 2005). Here, we tested whether such data could be used to deduce the patterns of co-expression of key transcription factors in the embryonic thalamus at an age that predates the establishment of thalamocortical connections.

Serial sections were downloaded from E13.5 embryos. Within the thalamus, cell densities varied from low to high (Figure 4) and cells could be counted manually in such areas (Figure $4 B$ ), but

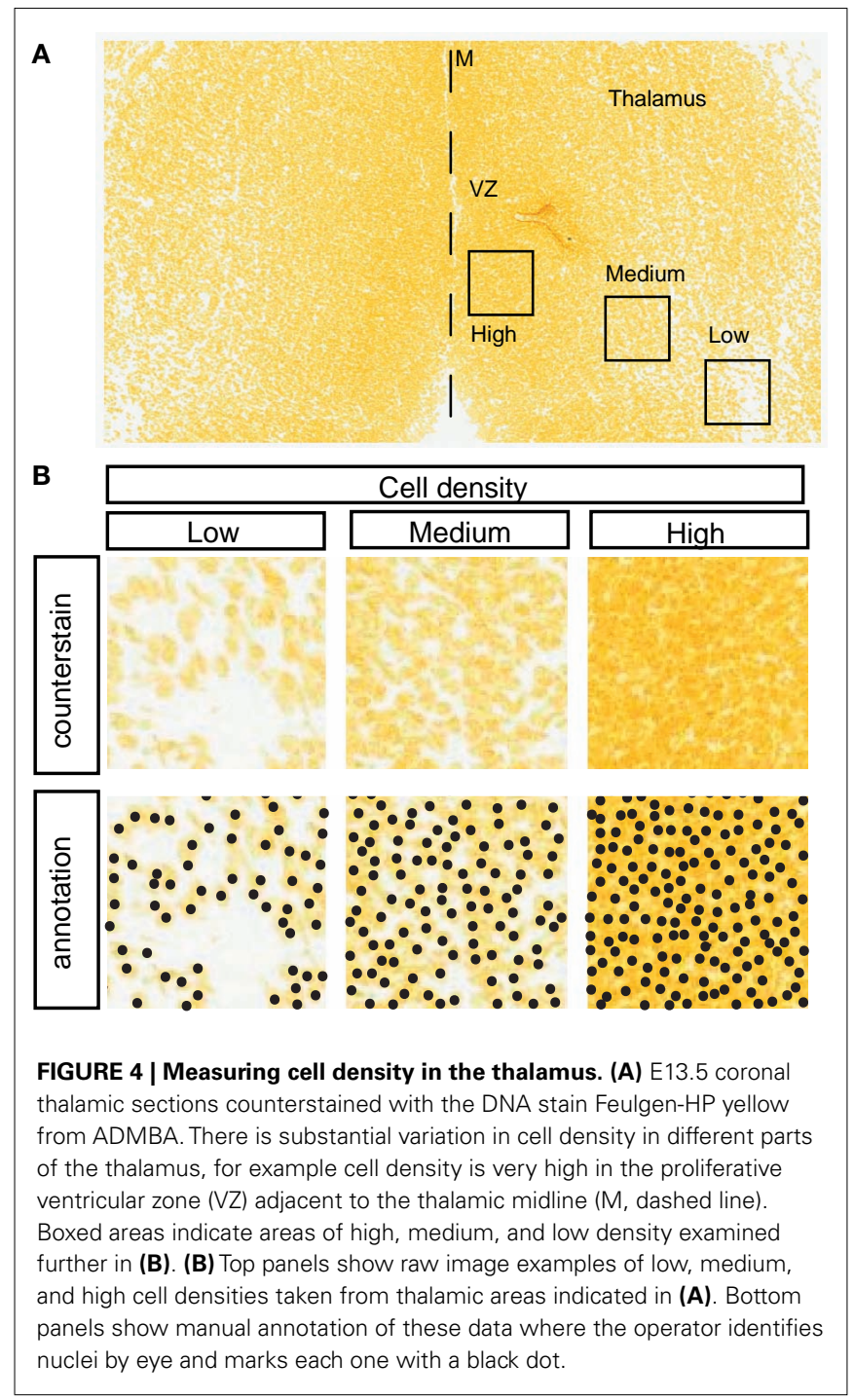

this was very time-consuming and so an automatic method was devised. The method was based on the use of Hessian matrices to describe mathematically local morphological features across an image, such as the curvatures of edges (Sato et al., 1998). In the ADMBA, counterstained nuclei have edges that are clear enough to allow the application of this approach. The calculation of the eigenvalues of the Hessian matrices and their subsequent classification allows the identification of round or oval shapes that correspond to cells. Data from this automated approach were compared with data obtained manually. For each image, the distance was calculated between each point allocated manually to a cell nucleus and its nearest neighbor among points allocated automatically, and where the distance was less than the radius of a nucleus $(5 \mu \mathrm{m})$ it was designated as a hit. This method gave hit rates of $90 \%$, indicating excellent correlation between the automatic and manual methods, and so the former was used to measure density across all E13.5 coronal sections through the entire thalamus. The surface of each section was divided into tiles $(20 \mu \mathrm{m} \times 20 \mu \mathrm{m})$ using a grid and cell density was measured in each tile.

Gene expression information was extracted from images of in situ hybridizations in the ADMBA based on color and brightness levels (an example of raw data is shown in Figure 5A). Each pixel across the image was categorized as: (i) no tissue (white; bright); (ii) non-expressing counterstained tissue (yellow; intermediate brightness); (iii) expressing tissue (gray/black; very dark). Each image was subdivided into $20 \mu \mathrm{m} \times 20 \mu \mathrm{m}$ tiles (Figure 5B; each small square represents one tile) to generate data that could be readily matched to the density information obtained as described above. The level of expression for each tile was calculated with:

tile expression level

$$
=\frac{\text { number of expressing pixels }}{\begin{array}{c}
\text { number of } \\
\text { expressing pixels }
\end{array}+} \begin{gathered}
\text { number of } \\
\text { non-expressing pixels }
\end{gathered}
$$

This gave a number for each tile indicating of how much of the tissue in it showed in situ hybridization staining. This number did not take into account cell density.

Data were then combined from in situ hybridizations with each of a series of patterning genes. Data from images of in situ hybridizations for one gene were matched to those from immediately adjacent images of the expression of another gene. The range of possible double-labeling was then estimated.

In cases where the expression level (as defined by the equation above) of one gene and that of a second gene within a given tile add to more than $100 \%$, we can conclude that there must be some double-labeling. The minimum proportion of doublelabeling tells us whether two genes necessarily overlap in a given tile, and how big that overlap is. For example, if the two genes cover 60 and $70 \%$, they must overlap by at least $30 \%$, although they could overlap by as much as $60 \%$. The maximum double-labeling gives a measure of how much of the tissue could be expressing both genes at the same time. Since we have values for the cell density in every tile (obtained as described above), we can combine data on proportions of double-labeled cells with cell densities in each tile to obtained values in terms of numbers of cells per tile (due to its 


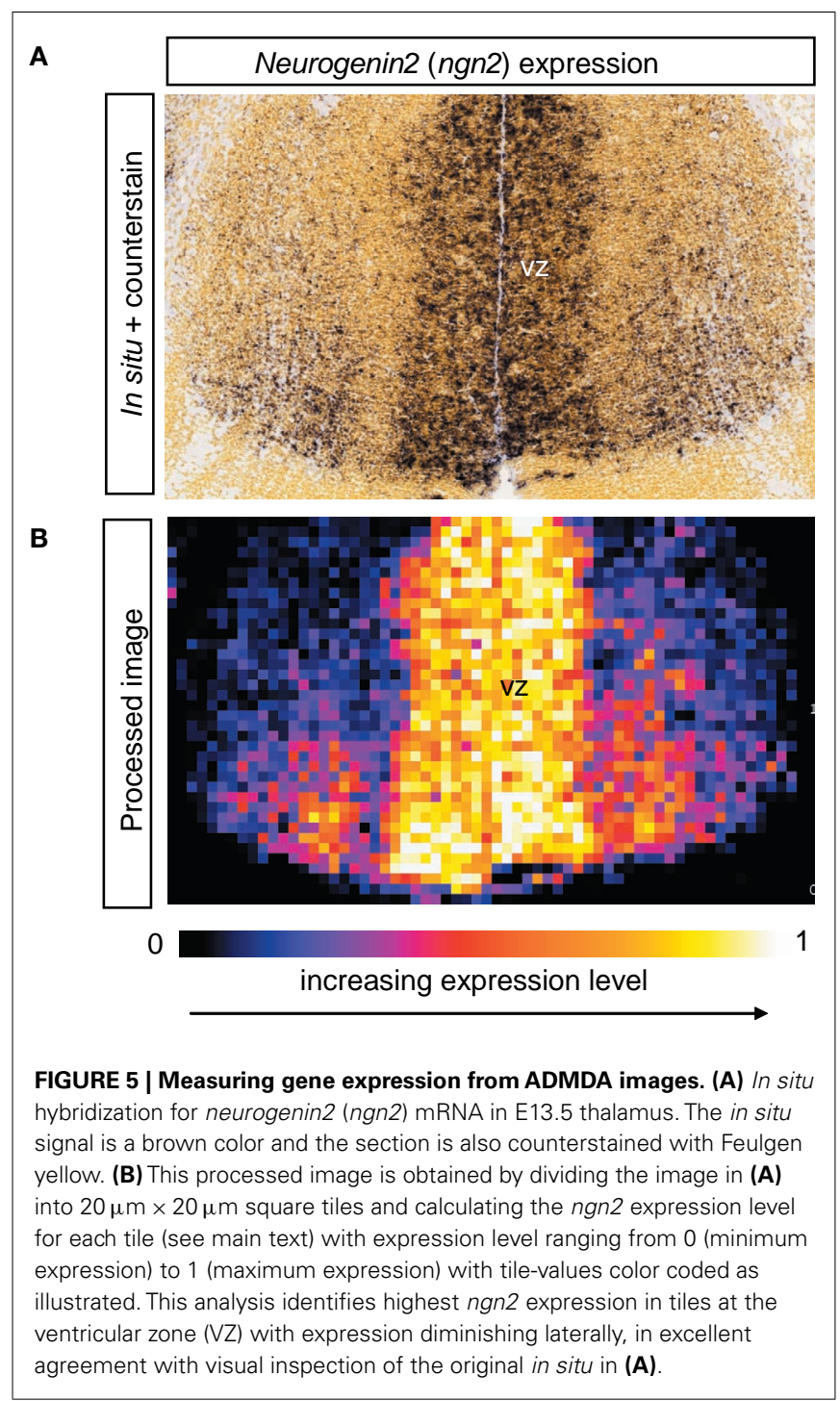

size, each tile contained a maximum of 11 cells). Thus, in each tile, the proportion of double-labeled cells was multiplied by the cell density.

The combination of minimum and maximum double-labeling values for each pair of genes provides information on the number of cells that must be co-expressing both genes and the potential number of cells that could. Examples of the outcomes of these analyses are shown in Figures 6-8. It is important to point out that these theoretical outcomes, which would need to be verified experimentally, necessarily involve assumptions. One of the assumptions, which might affect the estimates of minimum double-labeling, is that the expression pattern of each gene is similar through the depth of each $20 \mu \mathrm{m}$-thick section. This assumption might become less accurate in areas of high cell density in which, given an average cell diameter of about $10 \mu \mathrm{m}$, a maximum of two entire cells or one entire cell and two cell fragments might be located above each other at any point across the surface of the section. The more positions there are at which labeling is contributed by only one of the cells stacked above each other, the greater will be the overestimate of minimum double-labeling.

Figure 6 shows expression of the genes encoding the transcription factors Gbx2 and Ngn2, at two different rostrocaudal levels in the thalamus. A few cells in the strip of proliferating tissue adjacent to the third ventricle express $g b x 2$, but most cells throughout the population of differentiating thalamic cells express it. Expression is particularly strong at the lateral edges of the thalamus (upper arrow in Figure 6). On the other hand, ngn2 is expressed by proliferating cells adjacent to the ventricle as well as by differentiating cells positioned centrally within the thalamus. There is a gradient of $n g n 2$ expression, which increases with proximity to the zona limitans intrathalamica (ZLI), which marks the anterior boundary of the thalamus at this age. Examination of the possible range of $g b x 2-n g n 2$ co-expression across the thalamus revealed that many cells must co-express in a medial strip adjacent to the proliferative zone. Moving laterally, at least a few cells in the anterior part of the thalamus, toward the ZLI, must co-express whereas none are likely to co-express in the most lateral regions where $g b x 2$ expression is strong. Thus, the thalamus can be subdivided at E13.5 into an anteromedial zone in which cells express $g b \times 2$ and $n g n 2$ together and a lateral zone in which cells express $g b \times 2$ alone. The relative location of the regions of anterior thalamus in which cells co-express $g b \times 2$ and $n g n 2$ (lower arrow in Figure 6) correspond roughly to the relative location of the anterior nuclei of the adult thalamus. These nuclei are further subdivided and one can speculate that the most anteromedial zone of high double-labeling might develop into the mature anteromedial nuclei whereas the adjacent anterior zone with lower proportions of double-labeled cells might develop into another of the anterior group, e.g., the slightly more lateral anteroventral nucleus. Clearly, the early double-labeled cells need to be followed through development to confirm or refute such suggestions.

Figure 7 shows a further example, in this case of the expression and estimated co-expression of olig2 and ot $x 2$. In this case, we can deduce that the most significant numbers of cells that must, or might, co-express these transcription factors form a small subset of cells (arrows in Figure 7) expressing one or other alone within the body of the thalamus in a medial location. This relative position suggests that these cells might conceivably generate the centromedial nucleus of the mature thalamus.

Figure 8 shows a third example, in this case of the expression and estimated co-expression of $g b \times 2$ and otx2. In this case, co-expression levels are potentially greatest in anteromedial locations, suggesting a contribution of this combination of expression to the specification of the anteromedial nuclei.

Whereas the specifics of these suggested associations between gene co-expression patterns and mature nuclei are highly speculative, these analyses highlight an important overall conclusion, namely that the thalamus is extremely highly patterned molecularly from the earliest stages at which is contains significant number of postmitotic neurons and before it starts to send axons toward the cortex. This conclusion is reinforced by data on the expression of potential downstream effectors of the actions of these transcription factors, such as the Cadherins or the Eph/ephrins. Figure 9 shows, in a rostral-to-caudal series of sections through the E13.5 thalamus, 


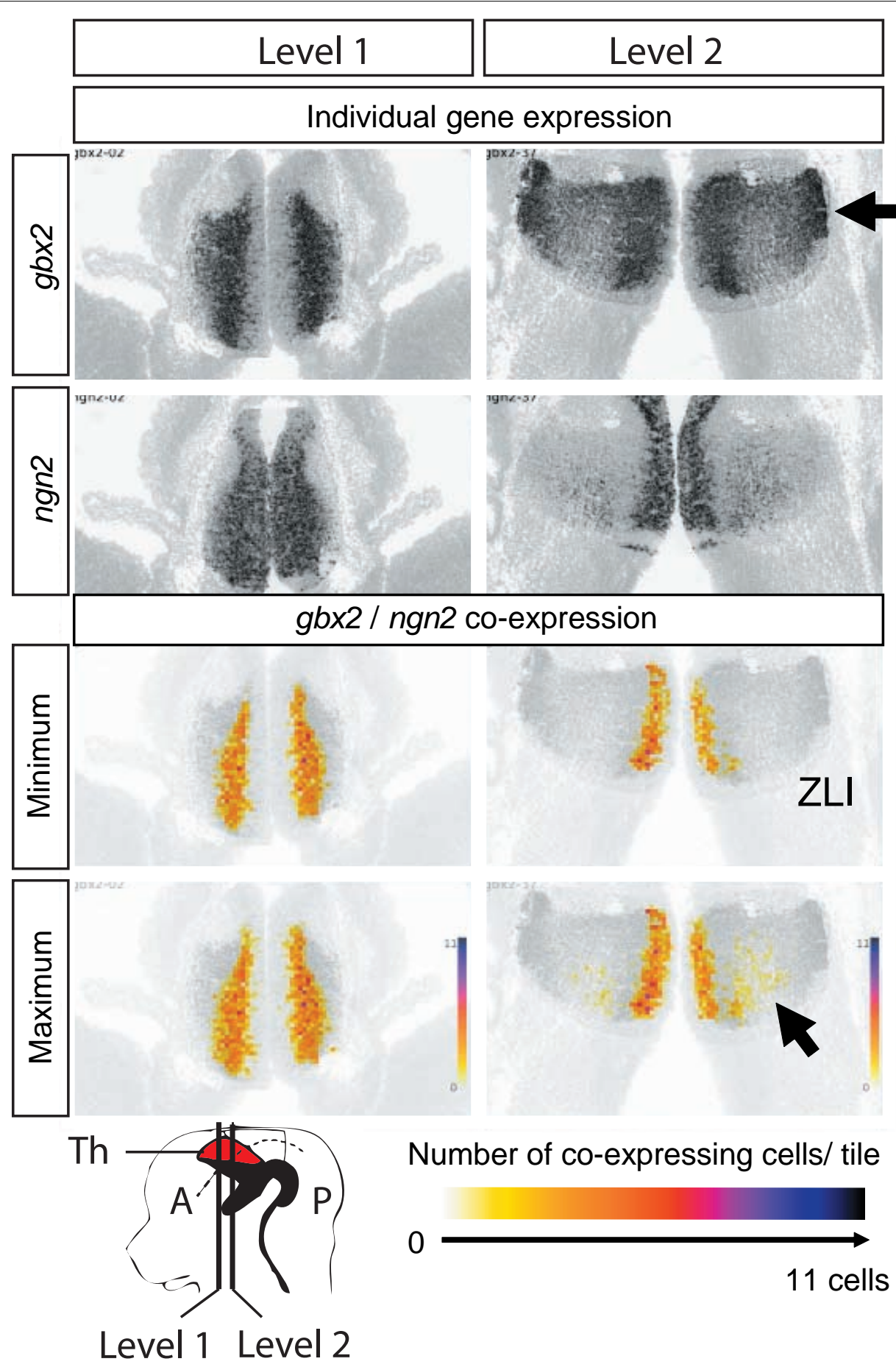

FIGURE 6 | Gbx2 and ngn2 co-expression in E13.5 thalamus. Top four panels show the raw data from ADMBA: in situ hybridizations for $g b \times 2$ and ngn2 at two coronal levels through the thalamus. The two levels are shown in the schematic at the bottom of the Figure. The lower four panels show representations of $g b x 2$ and $n g n 2$ co-expression obtained by combining gene expression and cell density information and calculating the (1) maximum and
(2) minimum number of cells in each $20 \mu \mathrm{m} \times 20 \mu \mathrm{m}$ tile co-expressing gbx2 and ngn2. The values for each tile range from 0 to 11 (the maximum number of cells that can fit in a single tile) and are color coded as illustrated at the bottom. Arrows indicate high level of $g b \times 2$ expression in the mantle zone (top) and double-label anteriorly close to the zona limitans intrathalamica (ZLI; bottom). In the schematic, the thalamus (Th) is in red. the complex expression patterns of two example, cadh 8 and epha4, revealing the molecular diversity and complex patterning of the cell surface constitutions of even the earliest thalamic cells. 


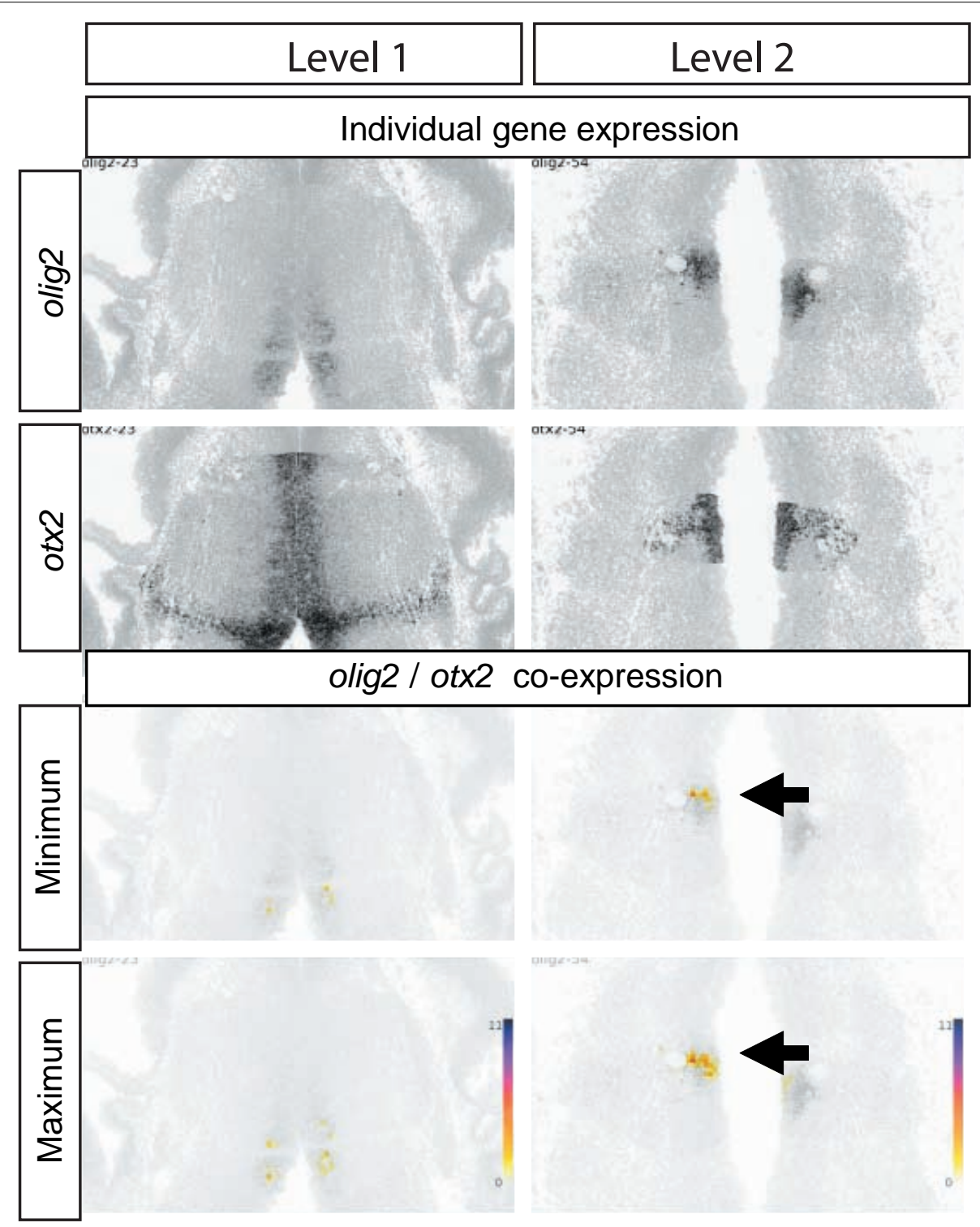

FIGURE 7 | Olig2 and otx 2 co-expression in E13.5 thalamus. Top four panels show the raw data from ADMBA: in situ hybridization for olig2 and otx2 at two coronal levels through the thalamus (see

Figure 6). The lower four panels show representations of olig2 and otx2 co-expression obtained by combining gene expression and cell density information and calculating the (1) maximum and (2) minimum number of cells in each $20 \mu \mathrm{m} \times 20 \mu \mathrm{m}$ tile co-expressing olig2 and otx2 (as in Figure 6). A small thalamic area in the ventricular zone is identified where two to six cells in each tile must be co-expressing olig2 and otx2 (arrows).

\section{EVIDENCE FOR THE IMPORTANCE IN THALAMIC AXONAL DEVELOPMENT OF REGIONALLY EXPRESSED THALAMIC TRANSCRIPTION FACTORS}

One of the ideas expressed earlier in this review is that early thalamic patterning is likely to invest in axons growing from different parts of the thalamus the ability to navigate in an ordered way to their appropriate area in the cerebral cortex. If this is the case we would predict that disruption of the expression of pattering molecules would disrupt the ordered development of thalamocortical axons. A number of mouse knock-out studies have shown that a variety of transcription factors play an important role in thalamocortical tract development. Mice lacking transcription factors such as Pax6, Mash1, Tbr1, and Ebf1 have thalamocortical axon pathfinding defects (Kawano et al., 1999; Miyashita-Lin et al., 1999; Tuttle et al., 1999; Pratt et al., 2000, 2002; Garel et al., 2002; Hevner et al., 2002; Jones et al., 2002) but it is not always clear whether this is because of a direct effect within the thalamus rather than an indirect result of defects elsewhere. In the case of Pax6, in vitro co-culture experiments have provided evidence that Pax6 expression is required within the thalamus itself for correct axon guidance (Pratt et al., 2000). Explants from wild type ventral telencephalon were cultured in contact with wild type or $\mathrm{Pax}^{-/-}$ 


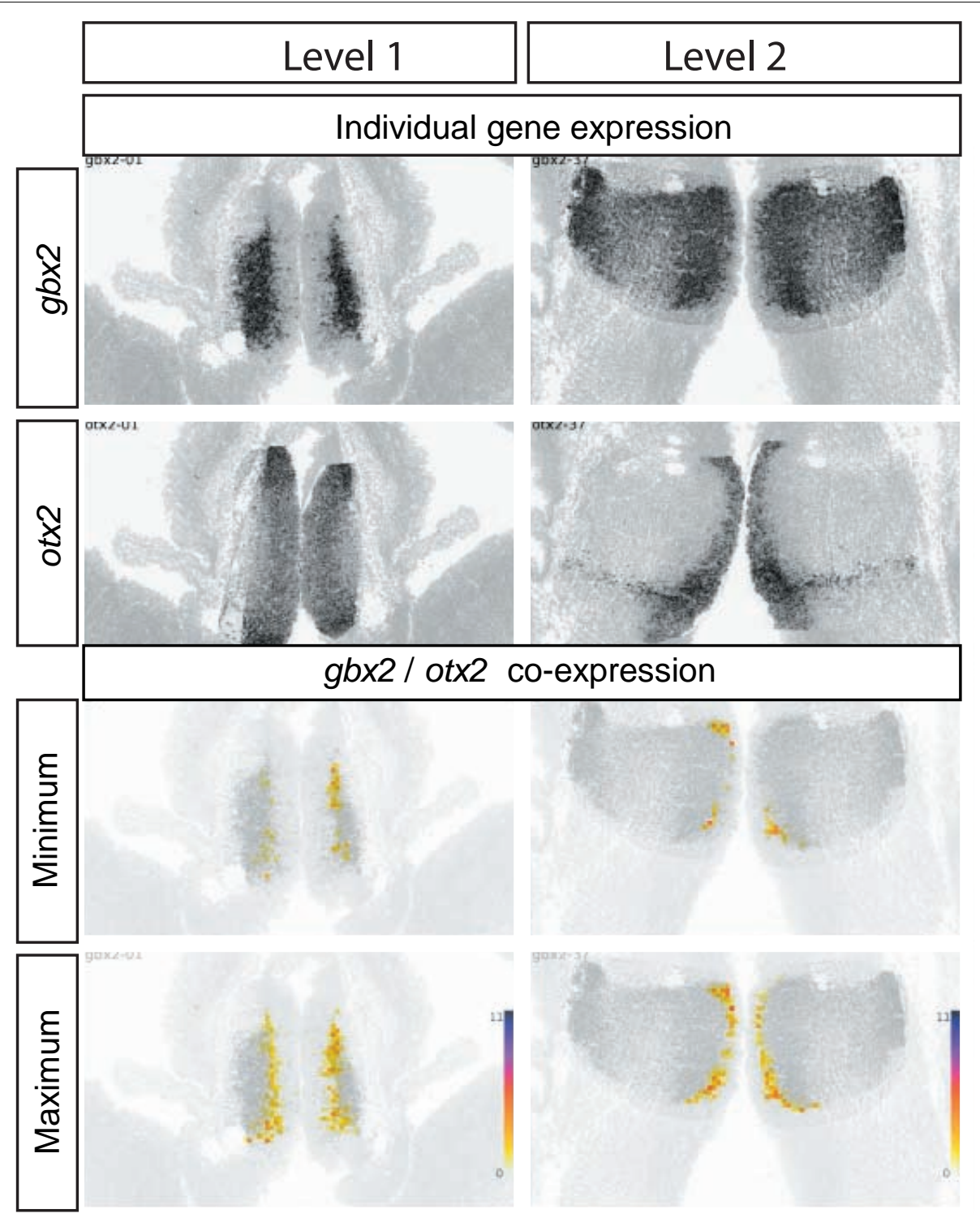

FIGURE 8 | Gbx2 and Otx2 co-expression in E13.5 thalamus. Top four panels show the raw data from ADMBA: in situ hybridizations for $g b x 2$ and otx2 at two coronal levels through the thalamus (see Figure 6). The lower four panels show representations of $g b x 2$ and ot 2 co-expression obtained by combining gene expression and cell density information and calculating the
(1) maximum and (2) minimum number of cells in each $20 \mu \mathrm{m} \times 20 \mu \mathrm{m}$ tile co-expressing olig2 and otx2 (as in Figure 6). A strip of co-expressing cells, narrow in the mediolateral axis but extending along the dorsoventral axis of the thalamus, is identified where two to six cells in each tile must be co-expressing $g b \times 2$ and ot $\times 2$. thalamus. When wild type thalamus was cultured with wild type ventral telencephalon, thalamic axons entered the ventral telencephalon and turned toward the cortex in a similar manner to that observed in vivo. When $P a x 6^{-/-}$thalamus was cultured with wild type ventral telencephalon a smaller number of thalamic axons entered the ventral telencephalon, they extended a shorter distance and failed to make a dorsal turn as in the previous experiment. This result showed that axons lacking Pax6 fail to grow in the correct manner even when confronted with an environment containing guidance cues that normal thalamic axons can respond to. This indicates that Pax6 expression is required within the thalamus for its axons to navigate.
One of the most interesting transcription factors in the present context is Ngn2, whose graded expression across the thalamus immediately prior to axonal outgrowth was discussed above and shown in Figure 6. By analyzing mice lacking Ngn2, Seibt et al. (2003) showed that Ngn2 specifies cell autonomously the projection of thalamic neurons to frontal cortical areas. The mechanism by which this is achieved is particularly interesting. Ngn2 determines the projection of thalamic neurons to specific cortical domains by specifying the responsiveness of their axons to cues encountered in tissues through which they navigate to attain the cortex. In other words, this transcription factor fits the role predicted by the hypothesis that early thalamic patterning is likely to 


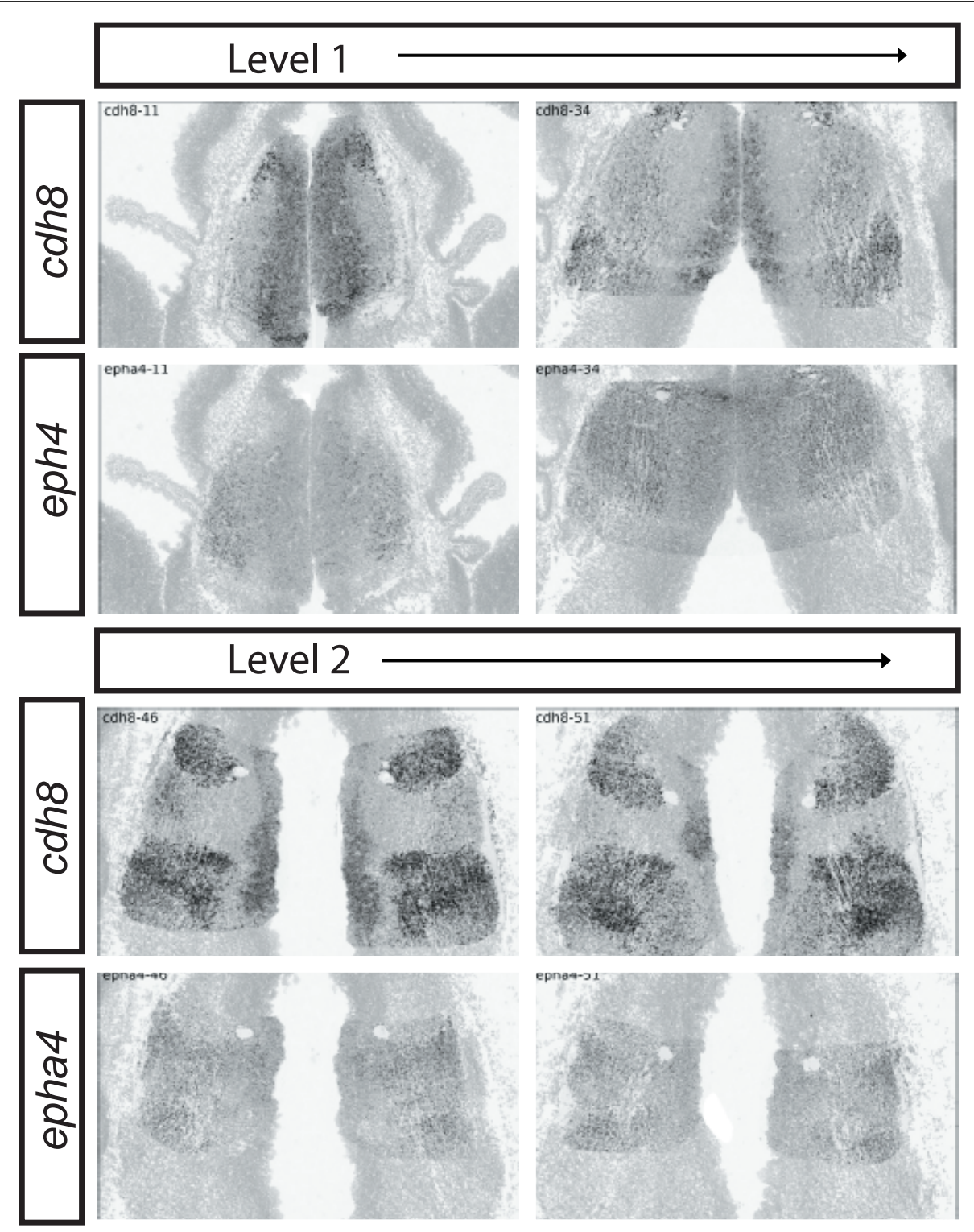

FIGURE 9 | Complex expression patterns of cell surface molecules in the developing thalamus at E13.5. In situ hybridizations for cadh8 and epha4 running from Level 1 past Level 2 (Levels shown in Figure 6). Images are taken from ADMBA.

invest in axons growing from different parts of the thalamus the ability to navigate in an ordered way to their appropriate area in the cerebral cortex.

The tissue through which thalamocortical axons navigate includes the ventral telencephalon, or subpallium, and much has been learned in recent years about the mechanisms that guide these axons through this and other intermediate regions. These mechanisms will be reviewed in the following sections.

\section{THE GUIDANCE OF AXONS FROM THE THALAMUS GUIDEPOST CELLS AND AXONS}

Before considering further the mechanisms that might ensure that axons from each part of the developing thalamus target their correct cortical area, we shall consider what is known about the mechanisms that guide the earliest axons out of the thalamus and toward the cortex. It seems likely that these early axons grow in an orderly way but as yet direct evidence on how ordered they are is lacking. Much of our understanding of these early phases of thalamocortical growth center on the results of studies examining the role of other sets of neurons and axons that pioneer or guide the thalamocortical axons in the direction of the cortex. This work predates our knowledge of the molecules that provide guidance and so we shall discuss the importance of pioneer axons first.

The importance of early pioneer or guidepost cells and axons in the development of persistent axonal pathways was recognized decades ago in other systems in other species. Guidepost cells are found at intermediate positions along the route of a particular axonal tract where they provide guidance information 
to navigating axons at important choice points. Initially described in the grasshopper limb bud, guidepost cells have since been proposed in other systems, including the developing mouse thalamocortical tract.

During grasshopper (Locusta migratoria) development the first two neurons that differentiate within the grasshopper limb bud designated as Til extend their axons along a defined route through the limb bud toward the central nervous system (Bate, 1976). Axons from later born neurons follow the same path as the Ti1 pioneer axons to form a major nerve trunk within the adult limb (Keshishian, 1980). The route taken by these pioneers is not a straight one, however: the axons make two near $90^{\circ}$ turns as they traverse the limb bud. At specific points along its route the Til axon makes contact with three cells designated F1, F2, and CT1. It was proposed that these cells act as intermediate targets for the Ti1 axon. These cells were termed "guidepost cells." Their importance was later demonstrated by a study which selectively destroyed the CT1 guidepost cells during limb bud development. It was found that in the absence of these cells the Til axon does not make the second $90^{\circ}$ turn toward the CNS and instead growth of the axon is either arrested at this point or continues abnormally within the limb bud. This demonstrated that guidepost cells are necessary for the guidance of pioneer axons in the grasshopper limb (Bentley and Caudy, 1983).

In the developing mouse thalamocortical system, it has been proposed that populations of guidepost cells are present along the route taken by thalamocortical axons and that these cells act as intermediate targets for thalamocortical axons or corticothalamic axons. These cells act in a different manner to those found in the grasshopper limb bud in that they extend axons, and it is thought that these axons then act as a scaffold to guide the later thalamocortical and corticothalamic axons. Axon tracing studies have identified populations of cells in two main locations that are proposed to act as guideposts (Figure 10).

First, cells within the reticular nucleus of the prethalamus are known to project axons to the thalamus (Ohara and Lieberman, 1985). These axons form along the same route that later thalamocortical axons will follow and are present throughout the period during which thalamocortical axons navigate through the diencephalon (Mitrofanis and Baker, 1993; Mitrofanis and Guillery, 1993). A second population of cells project axons to the thalamus from the internal capsule at the same time as axons from the reticular cell group (Métin and Godement, 1996; Molnár et al., 1998; Braisted et al., 1999). It has been suggested that these two populations of axons guide thalamocortical axons through the diencephalon and into the ventral telencephalon (reviewed in Molnar et al., 2003; Figure 10).

This hypothesis is compatible with the results of several studies in mutant mice. In mice lacking the transcription factor Mash1, thalamocortical axons do not cross the diencephalic-telencephalic border but instead remain within the diencephalon. In these mice there are no early projections from cells within the primitive internal capsule to the thalamus (Tuttle et al., 1999). In mice lacking the transcription factor Pax6, the thalamocortical tract also fails to form properly and, again, this corresponds with a failure of axonal projections from the internal capsule to the thalamus (Jones et al., 2002; Pratt et al., 2002). In mice that lack Emx2 thalamocortical

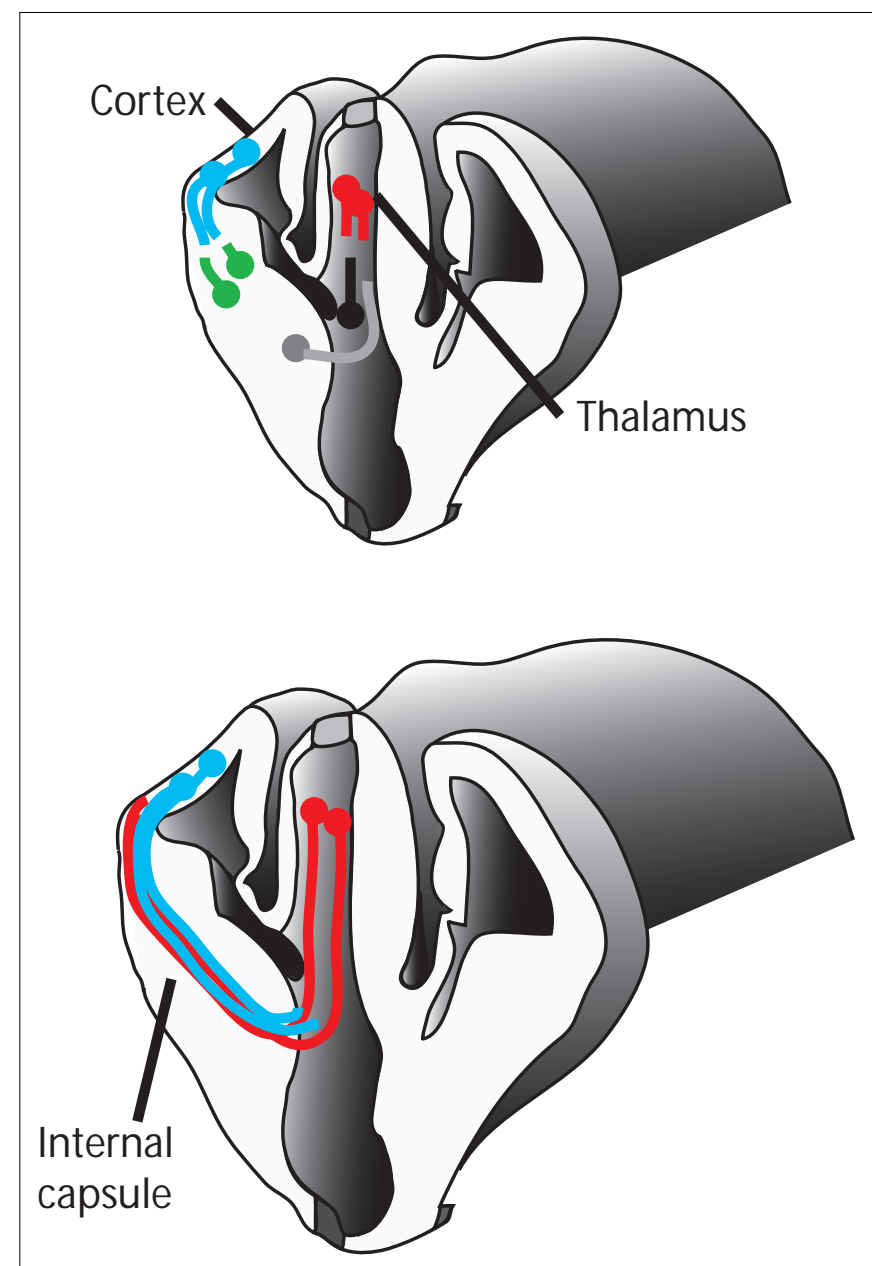

FIGURE 10 | Pioneer neurons and axons in the developing thalamocortical tract. As thalamic axons (red) grow they are thought to be guided by the axons of neurons in the reticular nucleus of the prethalamus (black) the site of the future internal capsule (gray). It has been suggested that these two populations of axons guide thalamocortical axons through the diencephalon and into the ventral telencephalon. Within the primitive internal capsule another population of cells project axons in the opposite direction, into the cortex (green). These axons are thought to guide descending corticothalamic axons (blue) into the ventral telencephalon across the pallial-subpallial boundary. Recent evidence suggests that for thalamic axons (red) to grow from subpallium to cortex they require guidance by cortical efferents (blue).

axons are misrouted in the ventral telencephalon and fail to reach the cortex. As in the previous examples this phenotype is associated with the loss of projections from the internal capsule and in addition a reduced number of axonal projections from cells within the prethalamic reticular nucleus (López-Bendito et al., 2002). Although these observations fit the proposal that the axons from guidepost cells located within the prethalamus and the primitive internal capsule are responsible for guiding thalamic axons into the ventral telencephalon, further work is needed since these mutant mice display wide-ranging morphological and molecular abnormalities and it is possible that the loss of guidepost cell axons may not be the primary cause of defects seen in the thalamocortical tract. More recent experiments by Zhou et al. (2008) demonstrated 
loss of both thalamocortical and corticothalamic axons in mice with conditional deletion of the Celsr3 gene restricted to the Dlx5/6-expressing cells in the ventral telencephalon around the site of the internal capsule. They suggested that a likely cause of these defects was the need for Celsr3 expression by guidepost cells, the probability of this explanation being increased by the restricted nature of the deletion to a region that contains such guidepost cells.

Within the primitive internal capsule another population of cells project axons in the opposite direction, into the cortex (Molnár et al., 1998; Figure 10). These axons are thought to guide descending corticothalamic axons into the ventral telencephalon across the PSPB (the important anatomical and gene expression boundary dividing the pallium from the subpallium). Recent experiments in our laboratory tested the hypothesis that descending corticofugal are, in their turn, important for guiding thalamocortical axons across the PSPB. The work used conditional mutagenesis to assess the effects of blocking corticofugal axonal development without disrupting thalamus, subpallium, or the PSPB. The results provided the most compelling evidence to date that for thalamic axons to grow across the PSPB from subpallium to cortex they require guidance by cortical efferents (Chen et al., 2012). The navigation of thalamic axons can be seen, therefore, as a series of steps with guidance being provided at each by different sets of reciprocal axons from intermediate or final targets.

\section{THE GROWTH OF THALAMOCORTICAL AXONS THROUGH THE VENTRAL TELENCEPHALON; THE CORRIDOR}

Guidance cues and receptors bound to the cell membranes can guide thalamic axons by providing permissive territory into which the axons are channeled. Recent studies have shown that thalamic axons will only navigate successfully through the medial ganglionic eminence (MGE) if cells from the lateral ganglionic eminence (LGE) expressing the guidance cue Neuregulin-1 migrate to form a permissive "corridor" through the otherwise non-permissive MGE (López-Bendito et al., 2006; Bielle et al., 2011a,b). This migration of cells from LGE to MGE is shown in Figure 11. The mechanisms that regulate it are not well understood but some experiments have implicated the transcription factor Pax6 and the repellant molecule Slit2 in this process (Simpson et al., 2009; Bielle et al., 2011a,b).

As thalamocortical axons navigate from the thalamus, Pax6 expression is found not only in the cortex, but also in the proliferative zone of the LGE (at lower levels than in the cortex) and in a stream of cells within the LGE descending on the ventral side of the internal capsule, as shown in Figure 11. The use of conditional mutagenesis to delete Pax6 from a specific region of Pax6 expression close to the internal capsule, through which thalamic axons navigate to cerebral cortex, caused many thalamic axons to take aberrant routes, either failing to turn normally into ventral telencephalon to form the internal capsule or exiting the developing internal capsule ventrally. In this case, early pioneer axons that project from the region of the future internal capsule to the thalamus were present, and the structure that was disrupted was the corridor, which was broader and less dense than normal (Figure 11). These findings indicate that ventral telencephalic Pax6 is important for formation of the corridor and the thalamic and cortical axons that grow through it (Simpson et al., 2009). In vivo

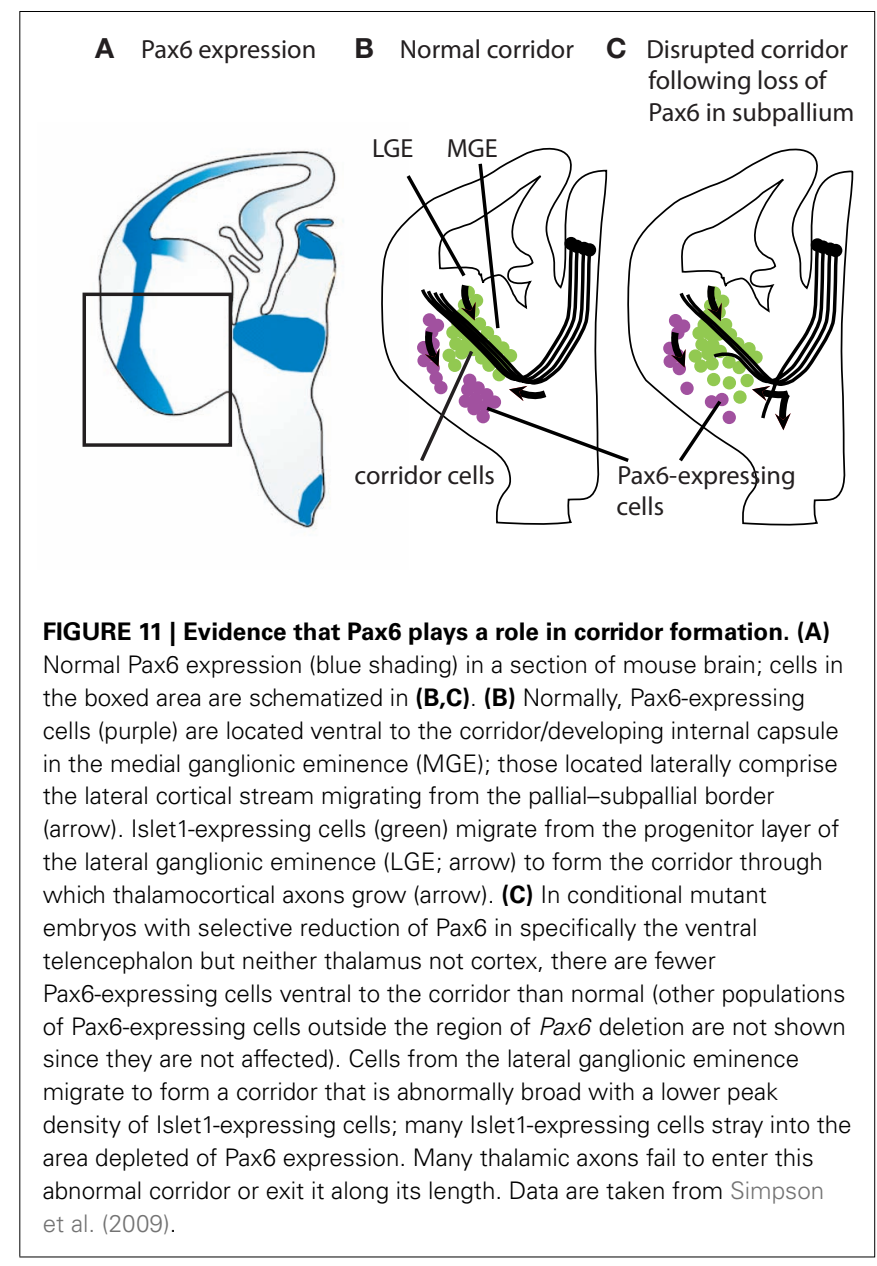

and ex vivo experiments in mice demonstrated that the midline repellent Slit2 orients migration of corridor neurons (Bielle et al., $2011 \mathrm{a}, \mathrm{b})$. Whether Pax6 might regulate molecules such as Slit2 to generate the corridor remains to be tested.

\section{REGULATORY MOLECULES IMPLICATED IN THE GUIDANCE OF THALAMIC AXONS THROUGH THE SUBPALLIUM}

A number of transcription factors other than Pax6 have been shown to be important for thalamocortical axons to navigate successfully through the subpallium. The most likely mechanism of action here is that these factors are required for the proper patterning of the subpallium and that, by regulating the cellular and molecular environment through which thalamocortical axons navigate, they create the necessary conditions and cues. For example, correct levels of the transcription factor Gli3, which is a well-known player in Sonic hedgehog signaling and whose mutation in humans causes brain and limb defects, are critical (Magnani et al., 2010). Mutant mice hypomorphic for Gli3 ( Gli3 ${ }^{P d n / P d n}$ ) show morphological abnormalities of the LGE associated with severe pathfinding defects of thalamocortical axons in the ventral telencephalon. Transplantation experiments demonstrated that the intrinsic ability of the Gli3 ${ }^{P d n / P d n}$ ventral telencephalon to guide thalamocortical axons is compromised, rather than the defects being caused primarily in the thalamus. The molecular networks that require 
regulation by Gli3 to ensure correct thalamocortical development are not known.

Another example comes from the work of Lakhina et al. (2007). They showed that the transcription factor Lhx 2 is essential for normal thalamocortical tract pathfinding because it has functions that are localized in the ventral telencephalon rather than in the thalamus. Interesting, the absence of $\mathrm{Lhx} 2$ in the ventral telencephalon selectively disrupts a subset of thalamic axons and their topography. Unlike the case with Gli3, this indicates that loss of Lhx2 causes a specific rather than a general perturbation of cues in this structure.

Crossing the knowledge-gap between high level transcription factors and the effectors of axons guidance that they ultimately regulate, we find quite a considerable body of literature on how the guidance cues themselves can influence the guidance of thalamocortical axons. It has been shown that certain guidance cues can have a chemoattractive or chemorepulsive effect on growing thalamic axons. One example of a well-known guidance molecule known to influence thalamocortical axon guidance in this way is Netrin-1. It is expressed in the ventral telencephalon and has been shown in vitro to act as an attractant for a subset of thalamic axons (Braisted et al., 1999, 2000; Bonnin et al., 2007). Netrin-1 may also act as a repulsive cue. Other studies have shown that Netrin-1 receptor DCC mediates an attractive response in the growth cone while receptor Unc5 mediates a repulsive response (reviewed by Moore et al., 2007). A close inspection of the dynamics of expression of different Netrin receptors by different sets of thalamic neurons is particularly important to understand the full activity of this molecule in thalamocortical axon guidance.

We now know that the topography of thalamocortical axon projections is initiated before they reach the cortex, in the ventral telencephalon. One of the interesting features of the expression of Netrin-1 in the ventral telencephalon is that it is graded from high levels anteriorly to low levels posteriorly. A question addressed by Powell et al. (2008) is whether this concentration gradient is required for the topographic sorting of thalamocortical axons to distinct cortical domains. Their work showed that Netrin-1 is a chemoattractant for anterior thalamic axons, in which DCC is highly expressed, but a chemorepellent for posterior thalamic axons, in which Unc5 receptors are highly expressed. DCC is required for the attraction of anterior thalamic axons to the Netrin-rich, anterior part of the ventral telencephalon whereas DCC and Unc5 receptors are required for the repulsion of posterior thalamocortical axons from this Netrin-rich region.

A study by Bonnin et al. (2007) has provided further information on how the activities of guidance molecules such as Netrin-1 can be modified by the actions of other molecules, thereby increasing the array of guidance cues offered to advancing thalamocortical axons. Altering serotonin levels in the embryonic mouse brain disrupts the precision of sensory maps formed by thalamocortical axons (e.g., Cases et al., 1996), suggesting that serotonin might influence thalamocortical axonal growth. Bonnin et al. (2007) found that posterior thalamocortical axons are repelled from Netrin-rich anterior ventral telencephalon in the presence of serotonin, suggesting that the distinct action brought about by combining serotonin and Netrin-1 is an important component in the subcortical sorting of thalamocortical axons en route to the cortex.

As well as Netrin-1 a number of other groups of proteins have been shown to act as guidance cues or receptors for thalamocortical axons. These include the Slits and their receptors, the Robos, which are thought to be particularly important for the repulsion of axons away from the hypothalamus (Bagri et al., 2002; Braisted et al., 2009). Mice deficient in Robo2 and, more dramatically, in both Robo1 and Robo2, display axon guidance errors in the development of thalamocortical connections (López-Bendito et al., 2007). Slit2 and Slit1/2 double mutants display malformations in thalamocortical targeting (Andrews et al., 2006).

A very recent and particularly striking example of how multiple guidance cues can combine to have often surprising effects on thalamocortical development is provided by the work of Bielle et al. (2011b). This work showed that the rostrocaudal topographic organization of the thalamocortical connections is initially established in the corridor in the ventral telencephalon (discussed above) and that the rostrocaudal gradients of Slit1 and Netrin-1 are critical for establishing this order in a rather surprising way. In these experiments, the authors found that for rostral thalamic axons Slit1 is a repellent and Netrin-1 had no chemotactic activity (in contradiction to previous findings discussed above: Powell et al., 2008). But when Slit1 and Netrin-1 were combined they generated attraction. The authors concluded that Slit 1 has a dual context-dependent role in thalamocortical navigation and that a combination of cues produces an emergent activity that neither of them has alone.

Other molecules involved in thalamocortical development include the Semaphorins, a family of genes that encode both membrane bound and diffusible guidance cues. Examples include Sema6A which is expressed by thalamic axons and Sema3C which is expressed in the ventral telencephalon and the cortex (Jones et al., 2002; Little et al., 2009). In Sema6A mutants, axons from the LGN of the thalamus are misrouted in the ventral telencephalon although, remarkably, the misrouted axons eventually do find their way to the visual cortex via alternate routes at postnatal stages and reestablish a normal pattern of thalamocortical connectivity (Little et al., 2009). These findings emphasize the point that, although intermediate cues in the ventral telencephalon are important for guidance, specificity can be achieved through cortical cues, indicating the multiplicity of mechanisms that result in correct thalamic axonal targeting in the cortex.

Another family of molecules strongly implicated in the development of the topography of thalamocortical projections is the Ephs and Ephrins (Dufour et al., 2003, 2006; Bolz et al., 2004; Torii and Levitt, 2005). Ephrin A5 has a gradient of expression in the intermediate tissue through which thalamocortical axons grow and EphA3, EphA4, and EphA7 have gradients of expression in the thalamus. Analysis of mutant mice has shown that Eph/ephrin genes control the topography of thalamocortical axons by sorting them in the ventral telencephalon (Dufour et al., 2003). As in the case of the modulation of the response of thalamocortical axons to netrin by serotonin discussed above, in the case of the Eph/ephrins it has been found that the cell adhesion molecules L1 and Close homolog of L1 (CHL1) can interact with individual EphA receptors and cooperate with them to guide specific sets of 
thalamocortical axons to their cortical targets (Demyanenko et al., 2011). These combinatorial actions are an important subject for future research.

\section{FUTURE PROSPECTS \\ THE IMPORTANCE OF COMBINATIONS OF REGULATORY MOLECULES FOR THALAMIC AXONAL GUIDANCE}

The development of precise, complex connectivity in the nervous system is regulated by a set of guidance molecules whose size is tiny compared to the number of connections that form. A question that requires answering is how so few guidance molecules specify the development of so many connections with such precision. In this review we have stressed the importance of levels and combinations of guidance molecules, with different levels and combinations having different effects on navigating thalamic growth cones. We can now appreciate that the range of instructions given to growing axons depends not only there being different guidance molecules with different properties but also on the fact that different levels, possibly other variables such as different isoforms, and different combinations of molecules modify the actions of these guidance cues. Many molecules that are not usually thought of primarily as guidance factors might, therefore, be involved in modulating the actions of the classical guidance molecules. We have already seen above that serotonin, thought of primarily as a neurotransmitter, can modify the actions of Netrin-1 (Bonnin et al., 2007). This means that the range of molecules that might be involved in specifying precise connectivity could be very much larger than the families of guidance molecules implicated to date.

\section{THE POTENTIAL IMPORTANCE OF CO-FACTORS IN MODULATING GUIDANCE}

As indicated above, additional specificity can be added to the function of relatively ubiquitous signaling pathways by molecules which act to modulate those pathways. For example, a potential mechanism for increasing specificity in this way is provided by enzymes that modify heparan sulfate (HS), the complex sulfated glycan component of cell surface and extracellular heparan sulfate proteoglycans. HS is modified by the addition and removal of sulfate moieties by specific heparan sulfotransferase and endosulfatase enzymes to generate a potentially enormous number of differentially sulfated structure (Turnbull et al., 2001). The high degree of structural diversity coupled with the fact that HS mediates the function of many morphogens and axon guidance molecules including Slit, Netrin, Wnt, FGF, VEGF, neuregulin, and Hh family members has prompted the "heparan sulfate code" hypothesis which postulates that differentially sulfated HS sugar structures act in combination with signaling proteins and their cell surface receptors to specify distinct cell fate and axon guidance responses (Bulow and Hobert, 2004; Lee and Chien, 2004; Holt and Dickson, 2005). Consistent with the hypothesis that this mechanism functions in the developing mammalian brain, distinct axon navigation phenotypes occur at the optic chiasm and

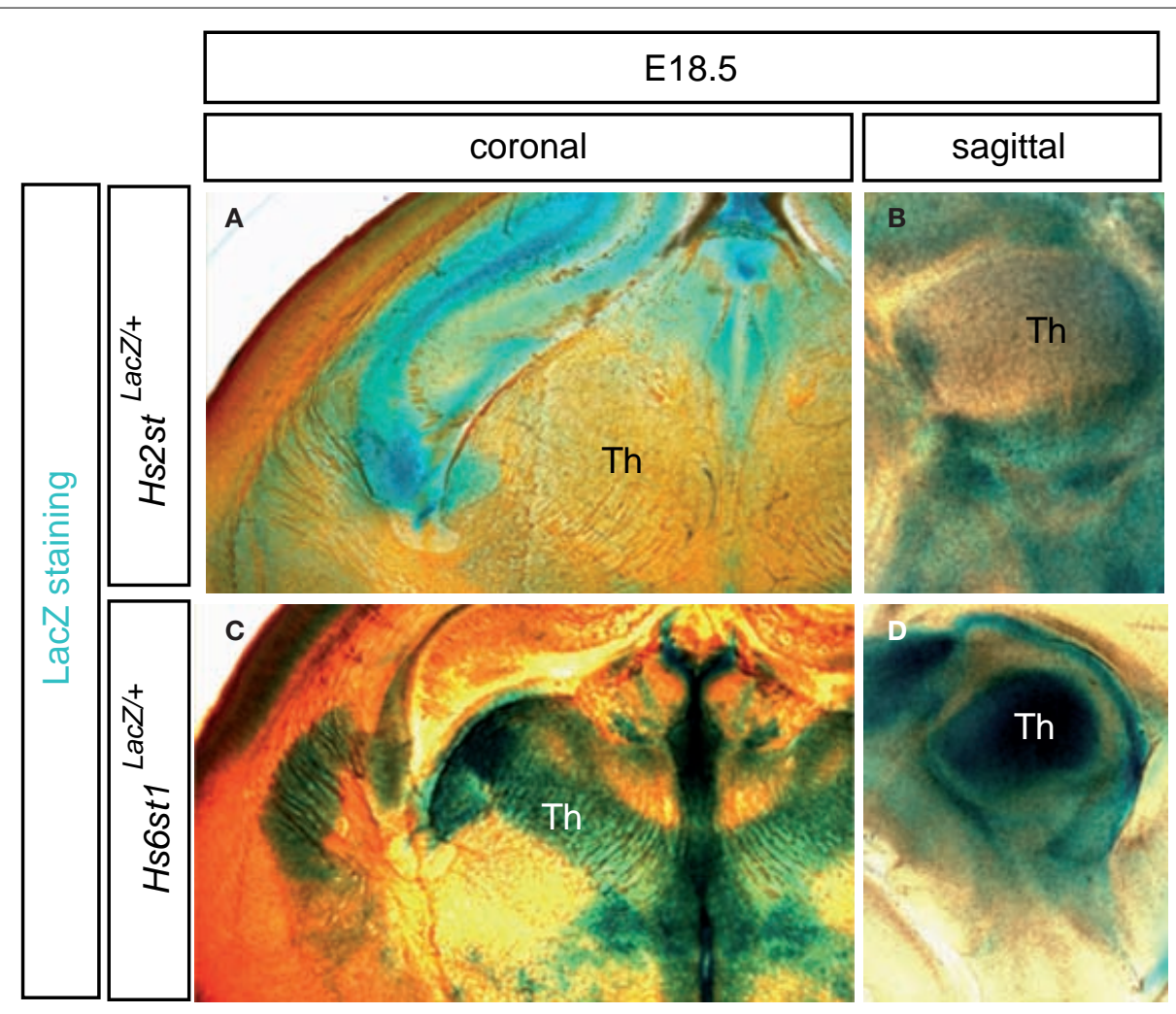

FIGURE 12 | Expression of heparan sulfate modifying enzymes Hs2st and $\mathbf{H s} 6 \mathbf{s t} \mathbf{1}$ in distinct patterns in the thalamus. Expression at E18.5 is revealed by LacZ staining (blue) of embryos heterozygous for a LacZ gene-trap integration in (A,B) Hs2st or (C, D) Hs6st1. Note that each enzyme is expressed in a highly distinct pattern. $(\mathbf{A}, \mathbf{C})$ are coronal sections and (B,D) are sagittal sections with anterior to the right. Th, thalamus. 
in the corpus callosum in mouse knock-out models lacking the HS modifying enzymes Ndst1, Hs2st, or Hs6stl (Grobe et al., 2005; Pratt et al., 2006; Conway et al., 2011a,b). While the role of HS modifying enzymes has not been studied in the thalamus and its connections in much detail to date, we have found that $\mathrm{Hs} 2 \mathrm{st}$ and Hs6st1 are expressed in remarkably regionalized, and to some extent complementary, patterns in the embryonic thalamus (Figure 12). Thalamic development and axonal projection rely on many of the same molecular pathways as the optic chiasm and corpus callosum, for example Netrin and Slit mediated axon guidance, so it is tempting to speculate that regionally expressed HS modifying enzymes create regions of different HS bioactivity in the developing thalamus which are important for its development and connectivity, most likely in highly specific ways.

\section{SCREENING FOR MORE GUIDANCE FACTORS}

Recently, researchers have started to broaden the search for genes that might be involved in regulating thalamocortical development.

\section{REFERENCES}

Andrews, W., Liapi, A., Plachez, C., Camurri, L., Zhang, J., Mori, S., Murakami, F., Parnavelas, J. G., Sundaresan, V., and Richards, L. J. (2006). Robol regulates the development of major axon tracts and interneuron migration in the forebrain. Development 133, 2243-2252.

Bagri, A., Marín, O., Plump, A. S., Mak, J., Pleasure, S. J., Rubenstein, J. L., and Tessier-Lavigne, M. (2002). Slit proteins prevent midline crossing and determine the dorsoventral position of major axonal pathways in the mammalian forebrain. Neuron 33, 233-248.

Bate, C. M. (1976). Pioneer neurones in an insect embryo. Nature 260, 54-56.

Bentley, D., and Caudy, M. (1983). Pioneer axons lose directed growth after selective killing of guidepost cells. Nature 304, 62-65.

Bielle, F., Marcos-Mondejar, P., Keita, M., Mailhes, C., Verney, C., Nguyen Ba-Charvet, K., Tessier-Lavigne, M., Lopez-Bendito, G., and Garel, S. (2011a). Slit2 activity in the migration of guidepost neurons shapes thalamic projections during development and evolution. Neuron 69, 1085-1098.

Bielle, F., Marcos-Mondéjar, P., LeyvaDíaz, E., Lokmane, L., Mire, E., Mailhes, C., Keita, M., García, N., Tessier-Lavigne, M., Garel, S., and López-Bendito, G. (2011b). Emergent growth cone responses to combinations of slitl and netrin 1 in thalamocortical axon topography. Curr. Biol. 21, 1748-1755.

Bolz, J., Uziel, D., Mühlfriedel, S., Güllmar, A., Peuckert, C., Zarbalis, K., Wurst, W., Torii, M., and Levitt, P. (2004). Multiple roles of ephrins during the formation of thalamocortical projections: maps and more. $J$. Neurobiol. 59, 82-94.

Bonnin, A., Torii, M., Wang, L., Rakic, P., and Levitt, P. (2007). Serotonin modulates the response of embryonic thalamocortical axons to netrin-1. Nat. Neurosci. 10, 588-597.

Braisted, J. E., Catalano, S. M., Stimac, R., Kennedy, T. E., Tessier-Lavigne, M., Shatz, C. J., and O'Leary, D. D. (2000). Netrin-1 promotes thalamic axon growth and is required for proper development of the thalamocortical projection. J. Neurosci. 20, 5792-5801.

Braisted, J. E., Ringstedt, T., and O'Leary, D. D. (2009). Slits are chemorepellents endogenous to hypothalamus and steer thalamocortical axons into ventral telencephalon. Cereb. Cortex 19(Suppl. 1), i144-i151.

Braisted, J. E., Tuttle, R., and O'leary, D. D. (1999). Thalamocortical axons are influenced by chemorepellent and chemoattractant activities localized to decision points along their path. Dev. Biol. 208, 430-440.

Bulow, H. E., and Hobert, O. (2004). Differential sulfations and epimerization define heparan sulfate specificity in nervous system development. Neuron 41, 723-736.

Carson, J. P., Ju, T., Lu, H. C., Thaller, C., Xu, M., Pallas, S. L., Crair, M. C., Warren, J., Chiu, W., and Eichele, G. (2005). A digital atlas to characterize the mouse brain transcriptome. PLoS Comput. Biol. 1, e41. doi:10.1371/journal.pcbi.0010041

Cases, O., Vitalis, T., Seif, I., De Maeyer, E., Sotelo, C., and Gaspar, P. (1996). Lack of barrels in the somatosensory cortex of monoamine oxidase A-deficient mice: role of a serotonin

One study used a forward genetic approach in which random mutagenesis was carried out in mice and mutations with effects on thalamocortical development were screened for by examining the morphology of the thalamocortical tract (the tract was specifically labeled in these mice since they carried a thalamus-expressed reporter transgene). Several lines carrying mutations in genes not previously known for roles in thalamocortical development were obtained (Dwyer et al., 2011; discussed in Lokmane and Garel, 2011). Such screens have the exciting potential to reveal additional genes regulating thalamocortical development without bias toward those whose proteins themselves have the ability to attract or repel growth cones. This approach is likely to identify new critically important co-factors whose analysis is probably going to be a major focus for future research in this area.

\section{ACKNOWLEDGMENTS}

We thank The Wellcome Trust UK and Medical Research Council UK for financial support of research in the authors' laboratory.

excess during the critical period. Neuron 16, 297-307.

Chen, Y., Magnani, D., Theil, T., Pratt, T., and Price, D. J. (2012). Evidence that descending cortical axons are essential for thalamocortical axons to cross the pallial-subpallial boundary in the embryonic forebrain. PLOS ONE (in press).

Conway, C. D., Howe, K. M., Nettleton, N. K., Price, D. J., and Mason, J. O. (2011a). Heparan sulfate sugar modifications mediate the functions of slits and other factors needed for mouse forebrain commissure development. J. Neurosci. 31, 1955-1970.

Conway, C. D., Price, D. J., Pratt, T., and Mason, J. O. (2011b). Analysis of axon guidance defects at the optic chiasm in heparan sulphate sulphotransferase compound mutant mice. J. Anat. 219, 734-742.

Demyanenko, G. P., Siesser, P. F., Wright, A. G., Brennaman, L. H., Bartsch, U., Schachner, M., and Maness, P. F. (2011). L1 and CHL1 cooperate in thalamocortical axon targeting. Cereb. Cortex 21, 401-412.

Dufour, A., Egea, J., Kullander, K., Klein, R., and Vanderhaeghen, P. (2006). Genetic analysis of EphA-dependent signaling mechanisms controlling topographic mapping in vivo. Development 133, 4415-4420.

Dufour, A., Seibt, J., Passante, L., Depaepe, V., Ciossek, T., Frisén, J., Kullander, K., Flanagan, J. G., Polleux, F., and Vanderhaeghen, P. (2003). Area specificity and topography of thalamocortical projections are controlled by ephrin/Eph genes. Neuron 39, 453-465.

Dwyer, N. D., Manning, D. K., Moran, J. L., Mudbhary, R., Fleming, M. S., Favero, C. B., Vock, V. M., O'Leary,
D. D., Walsh, C. A., and Beier, D. R. (2011). A forward genetic screen with a thalamocortical axon reporter mouse yields novel neurodevelopment mutants and a distinct emx2 mutant phenotype. Neural Dev. 6, 3 .

Garel, S., and Rubenstein, J. L. (2004). Intermediate targets in formation of topographic projections: inputs from the thalamocortical system. Trends Neurosci. 27, 533-539.

Garel, S., Yun, K., Grosschedl, R., and Rubenstein, J. L. (2002). The early topography of thalamocortical projections is shifted in Ebfl and Dlx1/2 mutant mice. Development 129, 5621-5634.

Grobe, K., Inatani, M., Pallerla, S. R., Castagnola, J., and Yamaguchi, Y. (2005). Cerebral hypoplasia and craniofacial defects in mice lacking heparan sulfate $\mathrm{Ndst} 1$ gene function. Development 132, 3777-3786.

Hevner, R. F., Miyashita-Lin, E., and Rubenstein, J. L. (2002). Cortical and thalamic axon pathfinding defects in Tbr1, Gbx2, and Pax6 mutant mice: evidence that cortical and thalamic axons interact and guide each other. J. Comp. Neurol. 447, 8-17.

Holt, C. E., and Dickson, B. J. (2005). Sugar codes for axons? Neuron 46, 169-172.

Jones, E. G. (2007). The Thalamus. Cambridge: Cambridge University Press.

Jones, L., López-Bendito, G., Gruss, P., Stoykova, A., and Molnár, Z. (2002). Pax6 is required for the normal development of the forebrain axonal connections. Development 129, 5041-5052.

Kataoka, A., and Shimogori, T. (2008). Fgf8 controls regional identity in the developing thalamus. Development $135,2873-2881$. 
Kawano, H., Fukuda, T., Kubo, K., Horie, M., Uyemura, K., Takeuchi, K., Osumi, N., Eto, K., and Kawamura, K. (1999). Pax-6 is required for thalamocortical pathway formation in fetal rats. J. Comp. Neurol. 408, 147-160.

Keshishian, H. (1980). The origin and morphogenesis of pioneer neurons in the grasshopper metathoracic leg. Dev. Biol. 80, 388-397.

Lakhina, V., Falnikar, A., Bhatnagar, L., and Tole, S. (2007). Early thalamocortical tract guidance and topographic sorting of thalamic projections requires LIM-homeodomain gene Lhx2. Dev. Biol. 306, 703-713.

Lee, J. S., and Chien, C. B. (2004). When sugars guide axons: insights from heparan sulphate proteoglycan mutants. Nat. Rev. Genet. 5, 923-935.

Little, G. E., López-Bendito, G., Rünker, A. E., García, N., Piñon, M. C., Chédotal, A., Molnár, Z., and Mitchell, K. J. (2009). Specificity and plasticity of thalamocortical connections in Sema6A mutant mice. PLoS Biol. 7, e98. doi:10.1371/journal.pbio. 1000098

Lokmane, L., and Garel, S. (2011). Screening for genes that wire the cerebral cortex. BMC Biol. 9, 1. doi:10.1186/1741-7007-9-1

López-Bendito, G., Cautinat, A., Sánchez, J. A., Bielle, F., Flames, N., Garratt, A. N., Talmage, D. A., Role, L. W., Charnay, P., Marín, O., and Garel, S. (2006). Tangential neuronal migration controls axon guidance: a role for neuregulin-1 in thalamocortical axon navigation. Cell 125, 127-142.

López-Bendito, G., Chan, C.-H., Mallamaci, A., Parnavelas, J., and Molnár, Z. (2002). The role of Emx2 in the development of the reciprocal connectivity between cortex and thalamus. J. Comp. Neurol. 451, 153-169.

López-Bendito, G., Flames, N., Ma, L., Fouquet, C., Di Meglio, T., Chedotal, A., Tessier-Lavigne, M., and Marín, O. (2007). Robol and Robo2 cooperate to control the guidance of major axonal tracts in the mammalian forebrain. J. Neurosci. 27, 3395-3407.

López-Bendito, G., and Molnár, Z. (2003). Thalamocortical development: how are we going to get there? Nat. Rev. Neurosci. 4, 276-289.

Magnani, D., Hasenpusch-Theil, K., Jacobs, E. C., Campagnoni, A. T., Price, D. J., and Theil, T. (2010). The Gli3 hypomorphic mutation Pdn causes selective impairment in the growth, patterning, and axon guidance capability of the lateral ganglionic eminence. J. Neurosci. 30, 13883-13894.

Métin, C., and Godement, P. (1996). The ganglionic eminence may be an intermediate target for corticofugal and thalamocortical axons. J. Neurosci. 16, 3219-3235.

Mitrofanis, J., and Baker, G. E. (1993). Development of the thalamic reticular and perireticular nuclei in rats and their relationship to the course of growing corticofugal and corticopetal axons. J. Comp. Neurol. 338, 575-587.

Mitrofanis, J., and Guillery, R. W. (1993). New views of the thalamic reticular nucleus in the adult and the developing brain. Trends Neurosci. 16, 240-245.

Miyashita-Lin, E. M., Hevner, R., Wassarman, K. M., Martinez, S., and Rubenstein, J. L. (1999). Early neocortical regionalization in the absence of thalamic innervation. Science 285, 906-909.

Molnár, Z., Adams, R., and Blakemore, C. (1998). Mechanisms underlying the establishment of topographically ordered early thalamocortical connections in the rat. J. Neurosci. 18, 5723-5745.

Molnar, Z., Higashi, S., and LopezBendito, G. (2003). Choreography of early thalamocortical development. Cereb. Cortex 13, 661-669.

Moore, S. W., Tessier-Lavigne, M., and Kennedy, T. E. (2007). Netrins and their receptors. Adv. Exp. Med. Biol. 621, 17-31.

Nakagawa, Y., and O’Leary, D. D. (2001). Combinatorial expression patterns of lim-homeodomain and other regulatory genes parcellate developing thalamus. J. Neurosci. 21, 2711-2725

Ohara, P. T., and Lieberman, A. R. (1985). The thalamic reticular nucleus of the adult rat: experimental anatomical studies. J. Neurocytol. 14, 365-411.

Powell, A. W., Sassa, T., Wu, Y., TessierLavigne, M., and Polleux, F. (2008). Topography of thalamic projections requires attractive and repulsive functions of Netrin-1 in the ventral telencephalon. PLoS Biol. 6, el16. doi:10.1371/journal.pbio.0060116

Pratt, T., Conway, C. D., Tian, N. M., Price, D. J., and Mason, J. O. (2006). Heparan sulphation patterns generated by specific heparan sulfotransferase enzymes direct distinct aspects of retinal axon guidance at the optic chiasm. J. Neurosci. 26, 6911-6923.
Pratt, T., Quinn, J. C., Simpson, T. I. West, J. D., Mason, J. O., and Price, D. J. (2002). Disruption of early events in thalamocortical tract formation in mice lacking the transcription factors Pax6 or Foxg1. J. Neurosci. 22, 8523-8531.

Pratt, T., Vitalis, T., Warren, N., Edgar, J. M., Mason, J. O., and Price, D. J. (2000). A role of Pax6 in the normal development of dorsal thalamus and its cortical connections. Development 127, 5167-5178.

Price, D. J., Kennedy, H., Dehay, C. Zhou, L., Mercier, M., Jossin, Y., Goffinet, A. M., Tissir, F., Blakey, D., and Molnár, Z. (2006). The development of cortical connections. Eur. J. Neurosci. 23, 910-920.

Sato, Y., Nakajima, S., Shiraga, N., Atsumi, H., Yoshida, S., Koller, T., Gerig, G., and Kikinis, R. (1998). Three-dimensional multi-scale line filter for segmentation and visualization of curvilinear structures in medical images. Med. Image Anal. 2, 143-168.

Seibt, J., Schuurmans, C., Gradwhol, G., Dehay, C., Vanderhaeghen, P., Guillemot, F., and Polleux, F. (2003). Neurogenin2 specifies the connectivity of thalamic neurons by controlling axon responsiveness to intermediate target cues. Neuron 39, 439-452.

Sherman, S. M. (2007). The thalamus is more than just a relay. Curr. Opin. Neurobiol. 17, 417-422.

Sherman, S. M., and Guillery, R. W. (2005). Exploring the Thalamus and Its Role in Cortical Function. Cambridge: The MIT Press.

Simpson, T. I., Pratt, T., Mason, J. O., and Price, D. J. (2009). Normal ventral telencephalic expression of Pax6 is required for normal development of thalamocortical axons in embryonic mice. Neural Dev. 4, 19.

Suzuki-Hirano, A., Ogawa, M., Kataoka, A., Yoshida, A. C., Itoh, D., Ueno, M., Blackshaw, S., and Shimogori, T. J. (2011). Dynamic spatiotemporal gene expression in embryonic mouse thalamus. J. Comp. Neurol. 519, 528-543.

Torii, M., and Levitt, P. (2005). Dissociation of corticothalamic and thalamocortical axon targeting by an EphA7-mediated mechanism. Neuron 48, 563-575.

Turnbull, J., Powell, A., and Guimond, S. (2001). Heparan sulfate: decoding a dynamic multifunctional cell regulator. Trends Cell Biol. 11, 75-82.

Tuttle, R., Nakagawa, Y., Johnson, J. E. and O'Leary, D. D. (1999). Defects in thalamocortical axon pathfinding correlate with altered cell domains in Mash-1-deficient mice. Development 126, 1903-1916.

Van der Werf, Y. D., Witter, M. P., and Groenewegen, H. J. (2002). The intralaminar and midline nuclei of the thalamus; anatomical and functional evidence for participation in processes of arousal and awareness. Brain Res. Rev. 39,107-140.

Vue, T. Y., Aaker, J., Taniguchi, A., Kazemzadeh, C., Skidmore, J. M., Martin, D. M., Martin, J. F., Treier, M., and Nakagawa, Y. (2007). Characterization of progenitor domains in the developing mouse thalamus. J. Comp. Neurol. 505, 73-91.

Vue, T. Y., Bluske, K., Alishahi, A., Yang, L. L., Koyano-Nakagawa, N., Novitch, B., and Nakagawa, Y. (2009). Sonic hedgehog signaling controls thalamic progenitor identity and nuclei specification in mice. J. Neurosci. 29, 4484-4497.

Yuge, K., Kataoka, A., Yoshida, A. C., Itoh, D., Aggarwal, M., Mori, S., Blackshaw, S., and Shimogori, T. (2011). Region-specific gene expression in early postnatal mouse thalamus. J. Comp. Neurol. 519, 544-561.

Zhou, L., Bar, I., Achouri, Y., Campbell, K., De Backer, O., Hebert, J. M., Jones, K., Kessaris, N., de Rouvroit, C. L., O'Leary, D., Richardson, W. D., Goffinet, A. M., and Tissir, F. (2008). Early forebrain wiring: genetic dissection using conditional Celsr3 mutant mice. Science 320, 946-949.

Conflict of Interest Statement: The authors declare that the research was conducted in the absence of any commercial or financial relationships that could be construed as a potential conflict of interest.

Received: 07 December 2011; paperpending published: 26 January 2012; accepted: 28 February 2012; published online: 15 March 2012.

Citation: Price DJ, Clegg J, Duocastella XO, Willshaw D and Pratt T (2012) The importance of combinatorial gene expression in early mammalian thalamic patterning and thalamocortical axonal guidance. Front. Neurosci. 6:37. doi: 10.3389/fnins.2012.00037

This article was submitted to Frontiers in Neurogenesis, a specialty of Frontiers in Neuroscience.

Copyright (C) 2012 Price, Clegg, Duocastella, Willshaw and Pratt. This is an open-access article distributed under the terms of the Creative Commons Attribution Non Commercial License, which permits non-commercial use, distribution, and reproduction in other forums, provided the original authors and source are credited. 